Rev Chil Salud Pública 2012;

Vol $16(2): 170-171$

Cifras de hoy en salud pública

YURI CARVAJAL (1)

(1)Escuela de Salud Pública. Facultad de Medicina.

Universidad de Chile.

Independencia 939.

Santiago. Chile.

ycarvajal@med.uchile.cl

\section{¿Cuánto mide el sector privado de salud en Chile?a}

\section{HOW TO MEASURE THE PRIVATE HEALTH SECTOR IN CHILE?}

Uno de los desafíos de la salud pública hoy es desarrollar una socio-historia de los mercados en salud pública. Vano sería intentar replicar una economía de la salud que ya ha alcanzado suficiente productividad por sí misma, pero tampoco tendría valor sentirse satisfecho con una lectura de la economía como una positividad al margen de teorías sobre la vida colectiva. La expresión economía designa un objeto de estudio y, a la vez, a una disciplina, que posee efectos preformativos sobre ese mismo objeto.

La salud pública se beneficiaría notablemente con la incorporación a su reflexión de la sociología de los mercados cuyo énfasis es comprender los mercados como agenciamientos calculativos y estudiar en base a qué distribuciones de técnicas intelectuales y equipamientos se configuran esas asimetrías ${ }^{1-4}$.

¿Por qué los mercados en salud en Chile han llegado tan tarde y se han desarrollado con tantas dificultades? ¿Existe solo una forma neoclásica de pensar los mercados? ¿Son los mercados lugares exentos de valores? Aunque no es esta la discusión que trae el documento que reseñamos, su contenido es un valioso aporte a la salud pública para desarrollar estos problemas.

El primero, un dimensionamiento básico: la porción de bienes y servicios de salud que pasan por un mercado de salud medido en precios es de un $43 \%$. O sea, el 7,8\% del gasto público en salud, es posible desglosarlo en un $4,4 \%$ estatal y el resto, $3,4 \%$ privado. Si se siguen las cifras de prestaciones, el $55 \%$ son privadas.

Este trabajo, usando un compilado de estadísticas procedente de fuentes diversas, entrega una excelente visión de la condición actual. Evidentemente hay vacíos, pero las agencias públicas no consideran los bienes y servicios de salud como un objeto plenamente económico, lo que hace difícil estimar la situación y realizar proyecciones. Por lo mismo, este estudio cobra importancia y pone el dedo sobre la necesidad de considerar seriamente que la medición en salud pasa por las estadísticas vitales, los diseños epidemiológicos y las encuestas, pero que -además- pasa en forma notable, por la economía.

Aunque el estudio se propone "dar una visión de la participación del sector privado en los tres niveles mencionados" (es decir, financiamiento, aseguramiento y provisión de prestaciones) como en toda buena descripción hay una hipótesis conductora: la importancia del sector privado, como productor, como oferente y, por supuesto, como oportunidad.

Esa importancia es indiscutible. En el informe aparecen algunos hechos que tienen particular relevancia. Por ejemplo, el marcado rezago respecto del sector público de las camas hospitalarias privadas y su desigual distribución geográfica, como se ilustra en el gráfico construido por nosotros en base a sus cifras. La Región de Aysén y el archipiélago de Chiloé lisa y llanamente carecen de camas privadas.

Otro aspecto preocupante es el crecimiento de la modalidad de Libre Elec-

\footnotetext{
a Comentario al documento Dimensionamiento del sector de salud privado en Chile. Actualización a cifras del año 2010. Clínicas de Chile A.G. Enero 2012. Disponible en http://www.clinicasdechile.cl/Dimensionamiento_2010.pdf.
} 


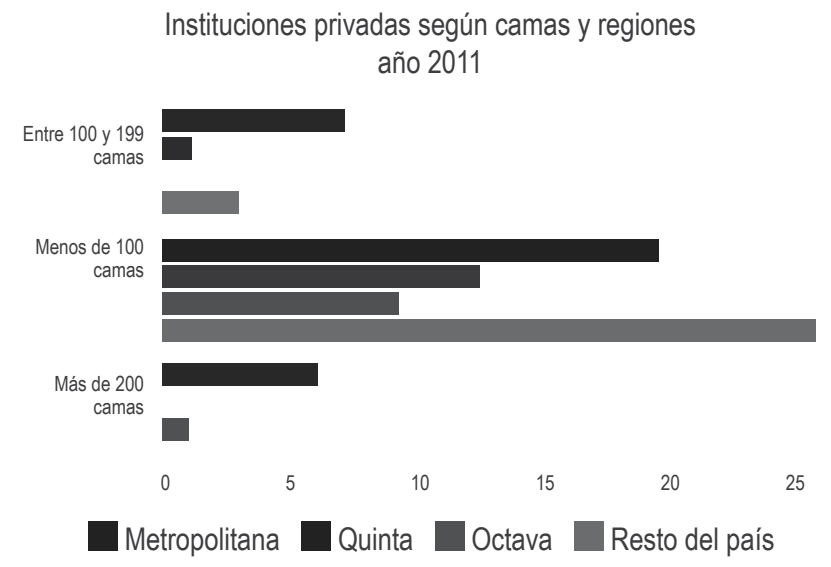

Figura 1. Distribución de establecimientos privados en macrozonas Chile 2010.

a los grupos A y B. No solo eso, sino que el grupo A creció un $17 \%$ entre el 2008 y el 2010. Paradójicamente el copago que deben hacer los afiliados a Fonasa por el día cama en prestaciones privadas es de un $98.3 \%$ versus el $22 \%$ en Isapres y la cobertura de medicamentos hospitalarios es de $0 \%$ y $77 \%$, respectivamente.

La expansión del PAD entre 1999 y el 2010 ha sido casi de 9 veces. Desde una cifra de 10.156 prestaciones ese primer año, hasta 96.134 este último. Que el PAD crezca a expensas de prestaciones inaplazables (Tabla 1) es

ción en Fonasa y el fuerte dinamismo del sistema de Pago Asociado a Diagnóstico (PAD)b. Si consideramos que el mar de fondo sobre el cual se dibujan estas cifras es la extrema desigualdad de la distribución del ingreso, podemos sospechar la magnitud del esfuerzo personal involucrado en el acceso de estos beneficiarios a Fonasa y el pago de bolsillo en que incurren para poder usar el PAD. Como el mismo documento señala, un $67 \%$ de los afiliados pertenece un problema. Una sugerencia para una alianza entre el seguro público y los prestadores privados se lee entre líneas de este estudio. Con eso es difícil disentir. Pero a partir de estos mismos datos habría que considerar las condiciones de aseguramiento para que los copagos y las diferencias geográficas no exacerbaran las injusticias y desigualdades que este mismo documento pone en evidencia.

Tabla 1. Evolución de algunas prestaciones PAD en el último quinquenio.

\begin{tabular}{lrrrrrr}
\hline \multicolumn{1}{c}{ Año } & $\mathbf{2 0 0 5}$ & \multicolumn{1}{c}{$\mathbf{2 0 0 6}$} & \multicolumn{1}{c}{$\mathbf{2 0 0 7}$} & $\mathbf{2 0 0 8}$ & $\mathbf{2 0 0 9}$ & $\mathbf{2 0 1 0}$ \\
\hline Parto & 43.508 & 50.051 & 55.482 & 53.977 & 60.242 & 58.672 \\
Colelitiasis & 4.536 & 5.183 & 5.348 & 6139 & 6.109 & 7.347 \\
Hernia abdominal complicada & 1.582 & 1.823 & 2.084 & 2199 & 2.021 & 2.391 \\
Hernia abdominal simple & 1.732 & 1.958 & 2.094 & 2064 & 2.073 & 2.374 \\
Fimosis & 1.153 & 1.437 & 1.672 & 1894 & 1.839 & 2.218 \\
Criptorquidia & 170 & 204 & 245 & 222 & 260 & 306 \\
$\begin{array}{l}\text { Acceso vascular complejo para } \\
\text { hemodiálisis }\end{array}$ & 146 & 173 & 253 & 226 & 213 & 268 \\
\hline
\end{tabular}

\section{REFERENCIAS}

1. Callon M. Why virtualism paves the way to political impotence. A reply to Daniel Miller's critique of The Laws of the Markets. Economic Sociology. 2006;6(2):3-20.

2. Muniesa F, Millo Y, Callon M. An introduction to market devices. Sociological Review. 2007 Issue Suplement;55:1-12.
3. Callon M, Méadel C, Rabeharisoa V. The economy of Qualities. Economy and Society. 2002; 31(2).194-217

4. Callon M, Muniesa $F$. Les marchés économiques comme dispositifs collectifs de calcul. Réseaux. 2003; 21(122): 189-233

\footnotetext{
b Los pagos asociados a diagnósticos son prestaciones privadas para afiliados a FONASA que implican un copago importante.
} 